\title{
DISPONIBILIDADE DE SILÍCIO PARA A CULTURA DO ARROZ, EM FUNÇÃO DE FONTES, TEMPO DE INCUBAÇÃO E CLASSES DE SOLO ${ }^{1}$
}

\author{
Cezesmundo Ferreira Gomes ${ }^{2}$, Marlene Estevão Marchetti ${ }^{3}$, \\ José Oscar Novelino $^{3}$, Munir Mauad ${ }^{3}$, Alessandra Mayumi Tokura Alovisi ${ }^{3}$
}

\section{ABSTRACT \\ AVAILABILITY OF SILICON FOR RICE CROP ACCORDING TO SOURCES, INCUBATION TIME, AND SOIL CLASSES}

Rice is a silicon accumulator, what benefits its growth and development, reducing cuticular transpiration and increasing the plant tolerance to pests and pathogens attacks. This study aimed to evaluate the incubation time effects of silicate sources on the $\mathrm{Si}$ availability and absorption and on rice plants growth. The experimental design was randomized blocks, in a $5 \times 2 \times 3$ factorial scheme, with four replications, two silicate sources (calcium silicate and steel slag), five incubation times $(1,14,35,63$, and 98 days), and three soils classes. The silicon dose used in the soil was $300 \mathrm{mg} \mathrm{dm}^{-3}$. The levels of soluble $\mathrm{Si}$ extracted by calcium chloride were evaluated in the soil, and, for plants, the dry matter of shoot and root, plant height, Si content and accumulation of the aerial part were evaluated. For all soil classes, the root dry matter yield was not influenced by silicon fertilization. The shoot dry matter index was higher with the application of calcium silicate. The highest shoot silicon accumulation occurred between the second and third incubation time, with higher concentration for the Oxisol.

KEY-WORDS: Oryza Sativa L.; silicate; Cerrado soil; steel slag.

\section{INTRODUÇÃO}

A produção mundial de arroz (Oryza sativa L.), atualmente, é de 421 milhões de toneladas anuais. O Brasil é considerado o maior consumidor ocidental de arroz, com consumo estimado em 13 milhões de toneladas ano ${ }^{-1}$ e produção anual de 11,3 milhões de toneladas (Conab 2008), em todo o território nacional. A produção de arroz, no Mato Grosso do Sul, foi estimada em 145,4 mil toneladas, para a safra 2009/2010, ocupando área de 26,5 mil hectares (Conab 2010).

\section{RESUMO}

O arroz é acumulador de silício, o qual beneficia seu crescimento e desenvolvimento, reduzindo a transpiração cuticular e aumentando a tolerância das plantas ao ataque de pragas e patógenos. Este trabalho objetivou avaliar os efeitos do tempo de incubação de fontes de silicato na disponibilidade e absorção de Si e no crescimento de plantas de arroz. O delineamento experimental foi o de blocos casualizados, em esquema fatorial $2 \times 5 \times 3$, com quatro repetições, duas fontes de silicato (silicato de cálcio e escória de siderurgia), cinco tempos de incubação (1, 14, 35, 63 e 98 dias) e três tipos de solo. A dose de silício foi de $300 \mathrm{mg} \mathrm{dm}^{-3}$. No solo, foram avaliados os teores de Si solúvel extraído por cloreto de cálcio e, nas plantas, avaliou-se a massa seca da parte aérea e raiz, altura de planta e teor e acúmulo de Si na parte aérea. Em todas as classes de solo, a produção de matéria seca das raízes não foi influenciada pela adubação silicatada. $\mathrm{O}$ índice de matéria seca da parte aérea foi maior, com a aplicação de silicato de cálcio. O maior acúmulo de silício, na parte aérea da planta, ocorreu entre o segundo e o terceiro tempo de incubação, com concentração mais elevada na classe Latossolo Vermelho distroférrico.

PALAVRAS-CHAVES: Oryza Sativa L.; silicato; solo sob Cerrado; escória de siderurgia.

Assim como outras gramíneas (cana-de-açúcar, sorgo, milheto, trigo, milho, capim kikuyo, etc.), o arroz é acumulador de $\mathrm{Si}$, que, embora não seja considerado elemento essencial, beneficia o crescimento e desenvolvimento da cultura, bem como reduz a transpiração cuticular e aumenta a tolerância das plantas ao ataque de pragas e patógenos (Korndörfer \& Datnoff 1995, Lima Filho 2005). As principais regiões produtoras de arroz no Brasil, como o Centro-Oeste, apresentam baixos teores de silício disponíveis, devido ao alto grau de intemperismo dos solos e à grande ocorrência de Neossolos

1. Trabalho recebido em ago./2010 e aceito para publicação em out./2011 (nº registro: PAT 10906/ DOI: 10.5216/pat.v41i4.10906).

2. Faculdade Anhanguera de Dourados, Dourados, MS, Brasil.E-mail: cezesmundo.gomes@aesapar.com.

3. Universidade Federal da Grande Dourados, Dourados, MS, Brasil.E-mails: marlenemarchetti@ufgd.edu.br, josenovelino@ufgd.edu.br,munirmauad@ufgd.edu.br, alessandraalovisi@ufgd.edu.br. 
Quartzarênicos, os quais apresentam baixos teores de Si disponível. Os teores de Si, nesta região, são, geralmente, inferiores a $2 \mathrm{mg} \mathrm{L}^{-1}$, na solução do solo (Lima Filho 2009).

As fontes de Si aprovadas pelo Ministério da Agricultura, Pecuária e Abastecimento, para uso na agricultura, são: escória silicatada, silicato de $\mathrm{Ca}$, silicato de $\mathrm{Ca}$ e $\mathrm{Mg}$, silicatos de $\mathrm{B}, \mathrm{Co}, \mathrm{Cu}, \mathrm{Fe}, \mathrm{Mn}$, Mo, Ni e Zn, silicato de K e termofosfatos (Brasil 2004).

O Brasil gera cerca de 6,25 milhões de toneladas de escória de siderurgia por ano, durante a produção do ferro-gusa, possibilitando uma fonte abundante e economicamente viável de Si (Pereira et al. 2003). Esta é uma fonte promissora para uso na agricultura, pois apresenta características adequadas, tais como alto conteúdo de Si solúvel, granulometria adequada, facilidade para a aplicação mecanizada, baixo custo, relações e quantidades de $\mathrm{Ca}$ e $\mathrm{Mg}$ equilibradas e baixos teores de elementos potencialmente tóxicos (Paim 2002, Lima Filho 2005).

Existem, na literatura, resultados promissores com a utilização de Si na agricultura, para a cultura do arroz, tais como aumento do número de folhas, massa seca de plantas e número de espiguetas por panícula, melhor formação e qualidade da casca dos grãos, maior altura de plantas e maior teor e acúmulo na parte aérea da planta (Lopes 1997, Korndörfer et al. 1999, Gong et al. 2003, Bittencourt et al. 2004, Tokura et al. 2007), entretanto, outros autores (Bar- bosa Filho et al. 1998, Carvalho 2000, Mauad et al. 2003) encontraram resultados diferentes, dependendo das doses de Si aplicadas, tipo de cultivar de arroz e solo, bem como condições ambientais.

Desta forma, este trabalho objetivou avaliar os efeitos de tempos de incubação de dois silicatos na disponibilidade e absorção de Si e no crescimento de plantas de arroz, cultivadas em amostras de três classes de solos representativas do Mato Grosso do Sul.

\section{MATERIAL E MÉTODOS}

O experimento foi realizado em casa-de-vegetação, em Dourados (MS), de outubro de 2007 a março de 2008. Utilizaram-se três amostras de solos representativos do Estado do Mato Grosso do Sul, classificados, segundo Embrapa (2006), como Neossolo Quartzarênico órtico (RQo), Latossolo Vermelho distrófico (LVd) e Latossolo Vermelho distroférrico (LVdf).

As amostras dos solos foram coletadas à profundidade de 0-0,20 m, no horizonte A, secas ao ar, destorroadas, passadas por peneira com malha de $2 \mathrm{~mm}$ de abertura, homogeneizadas e submetidas a análises de caracterização química e física (Tabela 1).

O delineamento experimental foi o de blocos casualisados, com quatro repetições, com os tratamentos dispostos em esquema fatorial $2 \times 5 \times 3$, cujos fatores incluíram duas fontes de silicato (silicato de cálcio p.a. e escória de siderurgia da Silifertil - acia-

Tabela 1. Atributos químicos e físicos das três classes de solo utilizadas no experimento (Dourados, MS, 2007/2008).

\begin{tabular}{|c|c|c|c|}
\hline \multirow[b]{2}{*}{ Atributos do solo ${ }^{(1)}$} & \multicolumn{3}{|c|}{ Solos } \\
\hline & $\begin{array}{c}\text { Neossolo Quartzarênico } \\
\text { órtico }\end{array}$ & $\begin{array}{c}\text { Latossolo Vermelho } \\
\text { distrófico }\end{array}$ & $\begin{array}{l}\text { Latossolo Vermelho } \\
\text { distroférrico }\end{array}$ \\
\hline pH em água & 5,0 & 5,0 & 5,2 \\
\hline $\mathrm{pH}$ em $\mathrm{CaCl}_{2}$ & 4,2 & 4,1 & 4,2 \\
\hline M.O. $\left(\mathrm{g} \mathrm{kg}^{-1}\right)^{2}$ & 4,6 & 15,9 & 20,3 \\
\hline $\mathrm{Si}\left(\mathrm{CaCl}_{2} 0,01 \mathrm{~mol} \mathrm{~L}^{-1}\right)\left(\mathrm{mg} \mathrm{dm}^{-3}\right)^{(3)}$ & 1,6 & 1,8 & 14,0 \\
\hline P-Mehlich $1\left(\mathrm{mg} \mathrm{dm}^{-3}\right)$ & 1,0 & 1,0 & 1,0 \\
\hline P-remanescente $\left(\mathrm{mg} \mathrm{L}^{-1}\right)$ & 46,0 & 35,0 & 11,0 \\
\hline $\mathrm{Al}^{3+}\left(\mathrm{mmol} \mathrm{dm}^{-3}\right)$ & 6,8 & 12,9 & 20,3 \\
\hline $\mathrm{H}+\mathrm{Al}^{3+}\left(\mathrm{mmol} \mathrm{DM}^{-3}\right)$ & 28,0 & 53,0 & 111,0 \\
\hline $\mathrm{Ca}^{2+}\left(\mathrm{mmol} \mathrm{dm}^{-3}\right)$ & 2,0 & 1,0 & 6,7 \\
\hline $\mathrm{Mg}^{2+}\left(\mathrm{mmol} \mathrm{dm}^{-3}\right)$ & 0,0 & 0,0 & 4,0 \\
\hline $\mathrm{K}^{+}-$Mehlich $1\left(\mathrm{mmol} \mathrm{dm} \mathrm{dm}^{-3}\right)$ & 0,5 & 0,5 & 0,9 \\
\hline Soma bases - SB $\left(\mathrm{mmol} \mathrm{dm}^{-3}\right)$ & 2,5 & 1,5 & 11,6 \\
\hline Saturacão por bases - V $(\%)$ & 8,0 & 2,0 & 9,0 \\
\hline Densidade de partículas $\left(\mathrm{g} \mathrm{cm}^{-3}\right)$ & 2,8 & 2,8 & 3,2 \\
\hline Densidade do solo $\left(\mathrm{g} \mathrm{cm}^{-3}\right)$ & 1,4 & 1,4 & 1,1 \\
\hline Volume total poros - VTP $(\%)$ & 49,0 & 51,0 & 65,0 \\
\hline Argila $\left(\mathrm{g} \mathrm{kg}^{-1}\right)^{(1)}$ & 130,0 & 240,0 & 760,0 \\
\hline Silte $\left(\mathrm{g} \mathrm{kg}^{-1}\right)^{(1)}$ & 19,4 & 40,0 & 91,0 \\
\hline Areia $\left(\mathrm{g} \mathrm{kg}^{-1}\right)^{(1)}$ M.D. ${ }^{(2)}$ & 850,0 & 720,0 & 149,0 \\
\hline
\end{tabular}

${ }^{(1)}$ Embrapa (1999). ${ }^{(2)}$ Análise granulométrica pelo método do densímetro. ${ }^{(3)}$ Korndörfer et al. (2004). 
ria), cinco tempos de incubação com o solo $(1,14$, 35, 63 e 98 dias) e três classes de solos (RQo, LVd e LVdf). As fontes de Si foram aplicadas em dose única (300 $\mathrm{mg} \mathrm{dm}^{-3} \mathrm{de} \mathrm{Si}$ ), nas três amostras de solo, segundo Carvalho-Pupatto et al. (2004). Uma amostra da escória de siderurgia, em triplicata, foi submetida a caracterização física e química, segundo Korndörfer et al. (2004), e apresentou, como média, $78,1 \mathrm{~g} \mathrm{~kg}^{-1}$ de $\mathrm{Si}$, ou $167,3 \mathrm{~g} \mathrm{~kg}^{-1}$ de $\mathrm{SiO}_{2}$, enquanto o silicato de cálcio p.a. apresentou, em média, $13,1 \mathrm{~g} \mathrm{~kg}^{-1} \mathrm{de}$ $\mathrm{Si}$, ou $28,0 \mathrm{~g} \mathrm{~kg}^{-1} \mathrm{de}_{\mathrm{SiO}}$, ambos com granulometria inferior a $0,297 \mathrm{~mm}$.

Amostras de 3,6 $\mathrm{dm}^{3}$ de solo foram acondicionadas em sacos plásticos e incubadas com amostras dos silicatos, durante 1, 14, 35, 63 e 98 dias, com teor de água destilada suficiente para ocupar 60\% do volume total de poros (Embrapa 1997).

Subamostras de $3,5 \mathrm{dm}^{3}$ de cada material de solo, após os períodos de incubação com os silicatos, foram padronizadas com $\mathrm{Ca}$ e $\mathrm{Mg}$, utilizando-se carbonato de magnésio, carbonato de cálcio e sulfato de magnésio.

Antes da semeadura do arroz, foi adicionada ao solo uma solução nutritiva, contendo macro e micronutrientes, segundo Novais et al. (1991).

A adubação fosfatada foi realizada com o adubo superfosfato triplo, cujas doses de $\mathrm{P}\left(180 \mathrm{mg} \mathrm{dm}^{-3}\right.$, para o RQo; $210 \mathrm{mg} \mathrm{dm}^{-3}$, para o LVd; e $288 \mathrm{mg} \mathrm{dm}^{-3}$, para o LVdf) foram estimadas por solo, com base nos valores de P-remanescente, correspondentes ao terceiro nível de $\mathrm{P}$ a ser utilizado em estudo de adubação com este nutriente, em experimento em vasos, segundo Alvarez et al. (2000).

Aos 12, 24, 44, 60 e 70 dias após a semeadura, foram efetuadas adubações nitrogenadas em cobertura, nas doses de $20 \mathrm{mg} \mathrm{dm}^{-3}, 25 \mathrm{mg} \mathrm{dm}^{-3}, 30 \mathrm{mg} \mathrm{dm}^{-3}$, $20 \mathrm{mg} \mathrm{dm}^{-3}$ e $25 \mathrm{mg} \mathrm{dm}^{-3}$ de $\mathrm{N}$ (na forma de ureia), respectivamente. Ao final do período de incubação, uma amostra de solo de cada vaso foi seca ao ar, destorroada, homogeneizada e submetida à análise de $\mathrm{Si}$ solúvel em $\mathrm{CaCl}_{2}$, segundo Korndörfer et al. (2004).

Na planta, por ocasião da colheita, realizada aos 80 dias após a semeadura, foram avaliadas as seguintes características: altura de plantas $(\mathrm{cm})$, massa seca da parte aérea e raízes $\left(\mathrm{g}\right.$ planta $\left.{ }^{-1}\right)$ e teor de $\mathrm{Si}$ na massa seca da parte aérea $\left(\mathrm{g} \mathrm{kg}^{-1}\right)$, determinado segundo metodologia descrita em Korndörfer et al. (2004), e acúmulo de Si na massa seca da parte aérea.

Os dados foram submetidos a análise de variância, cujos efeitos dos fatores de variação foram testados pelo teste F, e, quando houve significância estatística, realizaram-se testes de média (Tukey), assim como as equações de regressão para tempo de incubação foram ajustadas utilizando-se o aplicativo computacional SAEG (Ribeiro Júnior 2001).

\section{RESULTADOS E DISCUSSÃO}

Constatou-se que houve efeito significativo das interações solo $\mathrm{x}$ tempo de incubação e fonte $\mathrm{x}$ tempo de incubação, não ocorrendo interação significativa para solo $\mathrm{x}$ fonte, nem para a interação solo $\mathrm{x}$ fonte $\mathrm{x}$ tempo de incubação, sendo o modelo quadrático o que melhor ajustou-se aos dados, para todas as classes de solo.

Quando se utilizou a escória de siderurgia, o maior teor de Si solúvel (37,29 $\left.\mathrm{mg} \mathrm{dm}^{-3}\right)$ foi obtido para o LVdf, aos 54 dias após a incubação, enquanto, para as outras duas classes de solo, o teor máximo de Si solúvel foi de 20,06 $\mathrm{mg} \mathrm{dm}^{-3}$ e 14,33 $\mathrm{mg} \mathrm{dm}^{-3}$, obtidos aos 44 e 48 dias, para o LVd e o RQo, respectivamente.

Para a fonte silicato de cálcio p.a., foi observado o mesmo comportamento, sendo que o maior teor de $\mathrm{Si}\left(37,20 \mathrm{mg} \mathrm{dm}^{-3}\right)$ foi obtido aos 74 dias de incubação, para o LVdf. Os teores máximos, para o $\operatorname{LVd}\left(17,43 \mathrm{mg} \mathrm{dm}^{-3}\right)$ e RQo $\left(14,55 \mathrm{mg} \mathrm{dm}^{-3}\right)$, foram atingidos aos 47 e 48 dias de incubação, respectivamente.

Os valores de Si solúvel em $\mathrm{CaCl}_{2}$, em função do tempo de incubação do $\mathrm{Si}$, para as duas fontes de silicatos, são apresentados na Figura 1.

Em relação ao comportamento destas duas fontes de Si no solo, observou-se que a escória de siderurgia disponibilizou mais rapidamente o Si solúvel no LVdf, enquanto o silicato de cálcio apresentou liberação mais lenta. Já para os outros dois solos, a liberação de Si foi semelhante, o que, provavelmente, está relacionado com a velocidade de liberação de $\mathrm{Si}$ no solo. Pode-se esperar que uma fonte de liberação mais lenta apresente efeito residual mais longo (Pereira et al. 2003).

Em ambas as fontes de $\mathrm{Si}$, foram observados os maiores valores de Si solúvel no LVdf e o menor no RQo, resultado este já esperado, em função do teor inicial de Si solúvel maior no LVdf (Tabela 1).

Os baixos teores de Si encontrados no RQo e $\mathrm{LVd}$ (inferior a $6 \mathrm{mg} \mathrm{dm}^{-3}$ ) e o valor médio para LVdf (6-24 $\mathrm{mg} \mathrm{dm}^{-3}$ ) (Tabela 1) estão relacionados aos teores e qualidade dos minerais constituintes destes 


\section{龟}

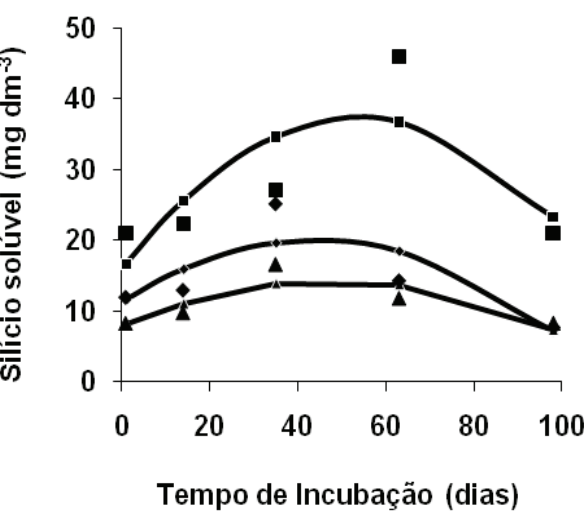

(a)

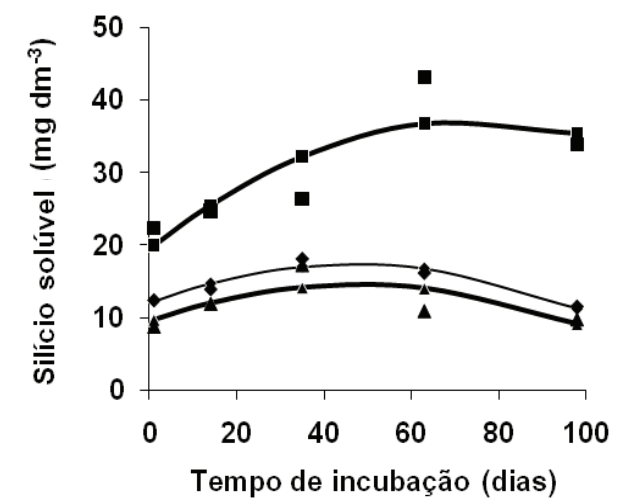

$\begin{array}{ll}\text { - } \mathrm{LVd}=12,06+0,2270 * * \mathrm{x}-0,0024 * \mathrm{x}^{2} & \mathrm{R}^{2}=0,92 * * \\ - \text { LVdf }=19,51+0,4759 * * \mathrm{x}-0,0032 * * \mathrm{x}^{2} & \mathrm{R}^{2}=0,71 * * \\ -\mathrm{RQo}=9,47+0,2114 * * \mathrm{x}-0,0022 * * \mathrm{x}^{2} & \mathrm{R}^{2}=0,53 * *\end{array}$ (b)

Figura 1. Silício solúvel em cloreto de cálcio $\left(\mathrm{mg} \mathrm{dm}^{-3}\right)$ nos solos, em função do tempo de incubação, para a escória de siderurgia (a) e silicato de cálcio (b) (Dourados, MS, 2007/2008).

solos (Barbosa Filho et al. 2000). Quanto maiores os teores de quartzo (mineral que praticamente não disponibiliza Si para a solução do solo), na fração areia, e baixos teores de mineral aluminossilicatado, na fração argila, menor a disponibilidade de Si para as plantas, avaliada por extratores químicos, como o $\mathrm{CaCl}_{2}$.

Os resultados observados para Si solúvel, no presente trabalho, corroboram os apresentados por Korndörfer et al. (1999), que encontraram a maior disponibilidade de Si para as plantas no Latossolo Vermelho distroférrico (LVdf), em relação ao Neossolo Quartzarênico (RQo), a qual, segundo os autores, está relacionada ao maior conteúdo de minerais aluminossilicatados (como aqueles do grupo da caulinita) presentes em níveis mais elevados no LVdf, os quais controlam a concentração de Si na solução deste solo, comparativamente ao RQo e ao LVd.

Todas as características das plantas foram significativamente influenciadas pelo fator solo ( $p<0,01$ ), enquanto, para o fator fonte de Si, houve efeito para a massa seca da parte aérea, teor e acúmulo de Si. Com relação ao tempo de incubação, ocorreu influência apenas para o teor e acúmulo de Si na massa seca da parte aérea $(\mathrm{p}<0,01)$. Houve efeito da interação Si x tempo de incubação para todas as variáveis, exceto para a massa seca de raízes.

A altura de plantas, para cada solo estudado, foi significativamente influenciada pelo fator tempo de incubação apenas para a classe RQo, sendo o modelo quadrático o que melhor se ajustou aos dados, com altura máxima de $43,0 \mathrm{~cm}$, obtida no tempo de 45 dias (Figura 2). Gong et al. (2003) obtiveram resultados semelhantes, para altura de plantas, com boas condições de umidade do solo e aplicação de Si.

Para matéria seca da parte aérea, nota-se efeito significativo para solo, fonte de Si e para a interação solo x tempo de incubação (Tabela 2).

No conjunto dos solos e dos tempos de incubação, observa-se o melhor desempenho do silicato de cálcio para a produção de massa seca da parte aérea (Tabela 2), o que pode ser atribuído à sua maior pureza e maior solubilidade, em comparação com a escória de siderurgia (Prado et al. 2001).

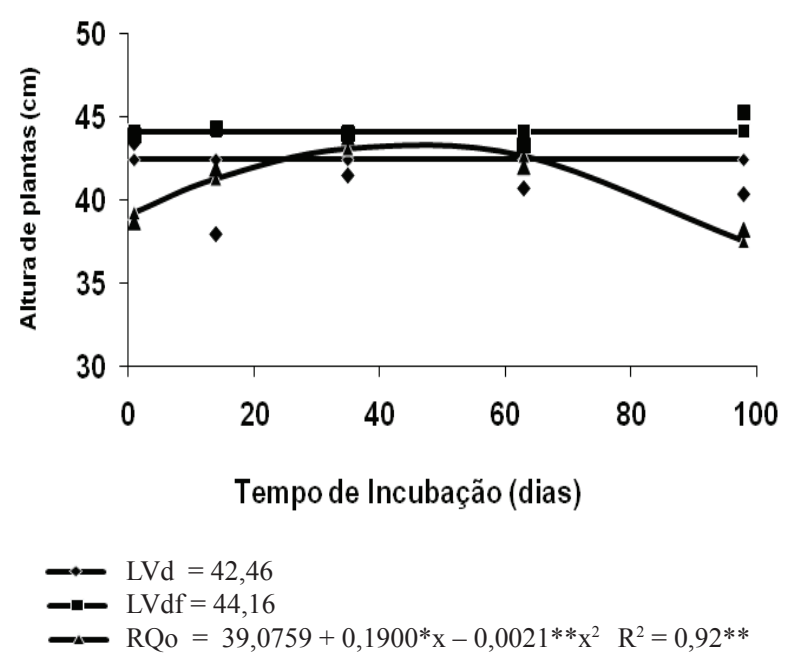

Figura 2. Altura de plantas (cm), em função do tempo de incubação, para cada solo estudado (Dourados, MS, 2007/2008). 
Tabela 2. Teor e acúmulo de silício e massa seca na parte aérea da planta, em função de duas fontes de silicato (Dourados, MS, 2007/2008).

\begin{tabular}{lccc}
\hline \multirow{2}{*}{ Fontes de silicato } & $\begin{array}{c}\text { Teor de } \\
\mathrm{Si}\end{array}$ & $\begin{array}{c}\text { Acúmulo } \\
\text { de Si }\end{array}$ & $\begin{array}{c}\text { Massa } \\
\text { seca }\end{array}$ \\
\cline { 2 - 4 } & $\mathrm{g} \mathrm{kg}^{-1}$ & \multicolumn{2}{c}{$\mathrm{mg} \mathrm{vaso}^{-1}$} \\
\hline Escória de siderurgia & $19,68 \mathrm{a}$ & $226,84 \mathrm{a}$ & $11,76 \mathrm{~b}$ \\
Silicato de cálcio p.a. & $15,77 \mathrm{~b}$ & $202,31 \mathrm{~b}$ & $12,44 \mathrm{a}$ \\
\hline
\end{tabular}

Médias diferem significativamente pelo teste Tukey, a $5 \%$. Valores médios de fontes no conjunto dos solos e dos tempos de incubação.

Nota-se que o modelo de curva quadrática foi o que melhor se ajustou aos dados, exceto para o LVdf, onde, dentre os modelos pesquisados, nenhum se ajustou aos dados. Foi observado decréscimo na produção até os 43 dias de incubação, para o LVd, enquanto, para o RQo, a maior produtividade de massa seca da parte aérea ocorreu aos 36 dias de incubação.

Tendo-se em vista a não significância da interação fonte de Si x tempo de incubação, equações de regressão foram ajustadas para a produção de matéria seca da parte aérea, como variável dependente de tempo de incubação, para cada classe de solo, no conjunto das fontes de Si (Figura 3).

Os resultados dos efeitos da adubação silicatada na massa seca da parte aérea de plantas de arroz são conflitantes na literatura, tanto em função de cultivares como de solo, tendo-se em vista os trabalhos de Mauad et al. (2003), com a cultivar IAC-202, em

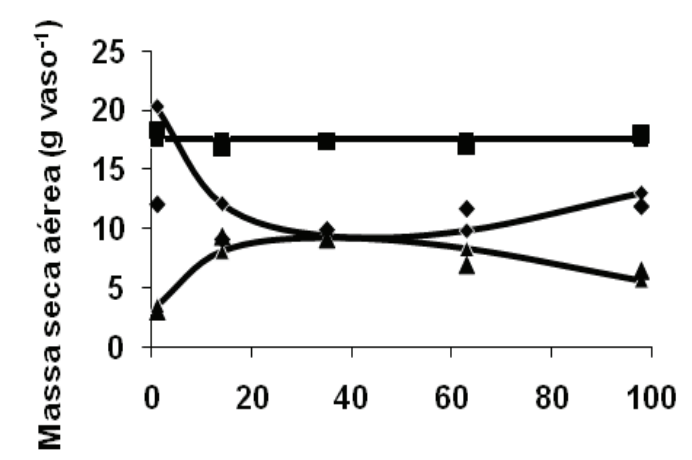

Tempo de incubação (dias)

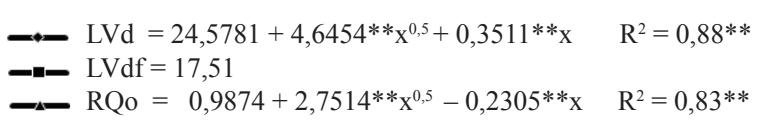

Figura 3. Massa seca da parte aérea $\left(\mathrm{g} \mathrm{vaso}^{-1}\right)$, em função do tempo de incubação, para cada solo estudado (Dourados, MS, 2007/2008).
Latossolo Vermelho distrófico; Tokura et al. (2007), com a cultivar BRS Primavera; e Faria Júnior et al. (2009), com as cultivares BRSMG Conai e BRSMG Curinga. Estes últimos autores, trabalhando em Neossolo Quartzarênico órtico, não encontraram incremento na produção de massa seca da parte aérea de plantas de arroz, com a aplicação de fontes de Si, enquanto Ramos et al. (2008) observaram aumento da massa seca da parte aérea da cultivar de arroz Rio Formoso, em experimento com Neossolo Quartzarênico órtico típico.

A produção de massa seca de raízes foi significativamente influenciada somente pelo fator solo, onde se percebe a melhor produção no LVdf, efeito intermediário para o LVd e o pior efeito para o RQo.

A produção de massa seca de raízes foi significativamente influenciada somente pelo fator solo, cuja comparação de médias, no conjunto de fontes e tempo de incubação, é apresentada na Tabela 3.

Estes resultados podem ser entendidos com base nos efeitos de uma mesma dose de Si aplicada aos solos, cujas características físicas, químicas, físico-químicas e mineralógicas são diferentes. Por exemplo, no LVdf, o mais argiloso e tamponado, é provável que os impactos negativos sobre ele, decorrentes da solubilização das fontes de $\mathrm{Si}$, tenham sido menores, pelo fato de apresentar maior superfície de adsorção de íons.

Tanto para o teor como para o acúmulo de $\mathrm{Si}$ na parte aérea, houve efeito dos fatores solo, fonte de Si, tempo de incubação e da interação solo x tempo de incubação (Tabela 2), onde observou-se que a escória de siderurgia foi a fonte que proporcionou maior teor e acúmulo de Si na parte aérea do arroz. Segundo Lopes (1997) e Bittencourt et al. (2004), o $\mathrm{pH}$ mais elevado pode aumentar a disponibilidade de Si no solo, tanto pela liberação de Si pelas fontes silicatadas como pela solubilização de polissilicatos originais dos solos.

Tabela 3. Massa seca das raízes, em função das classes de solo (Dourados, MS, 2007/2008).

\begin{tabular}{cc}
\hline \multirow{2}{*}{ Classes de solo } & Massa seca de raízes \\
\cline { 2 - 2 } & g vaso $^{-1}$ \\
\hline RQo & $2,28 \mathrm{c}$ \\
LVd & $3,25 \mathrm{~b}$ \\
LVdf & $5,69 \mathrm{a}$ \\
\hline
\end{tabular}

$\overline{\text { Médias diferem significativamente pelo teste Tukey, a } 5 \% \text {. Valores médios obtidos }}$ no conjunto de tempo de incubação e fontes de Si. 
Analisando-se a interação solo x tempo de incubação, para o teor de $\mathrm{Si}$, o modelo quadrático foi o que melhor se ajustou às classes de latossolos, enquanto o modelo linear foi o que melhor se ajustou ao RQo. O LVdf apresentou o maior teor de $\mathrm{Si}$ $\left(27,07 \mathrm{mg} \mathrm{dm}^{-3}\right)$ aos 25 dias de incubação. Já, o menor teor $\left(10,79 \mathrm{mg} \mathrm{dm}^{-3}\right)$ foi verificado para o RQo, aos 75 dias de incubação (Figura 4).

Analisando-se o acúmulo de Si (Figura 5), o modelo raiz quadrada foi o que melhor se ajustou às classes de solos. O LVdf apresentou o maior acúmulo de Si $\left(458,9 \mathrm{~g} \mathrm{vaso}^{-1}\right)$ aos 23 dias de incubação, enquanto o menor acúmulo de Si foi observado para RQo, cujo valor máximo $\left(140,22 \mathrm{~g}\right.$ vaso $\left.^{-1}\right)$ foi verificado aos 26 dias de incubação.
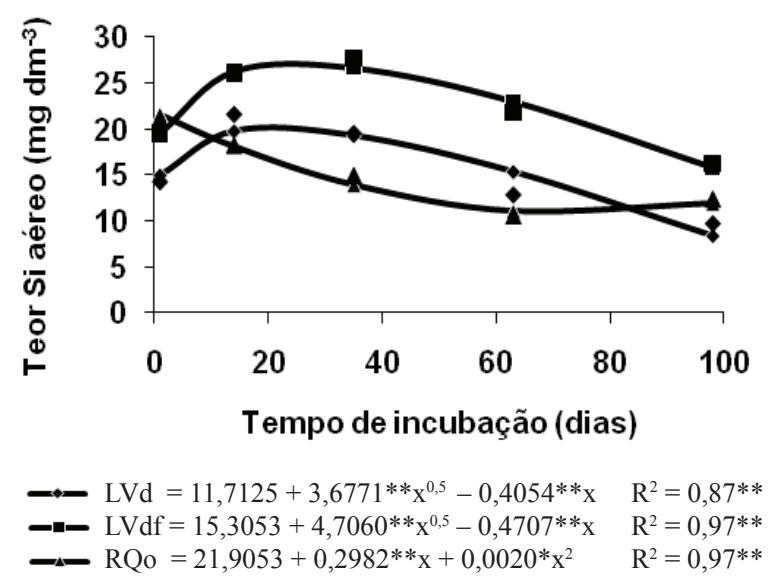

Figura 4. Teor de silício na parte aérea da planta de arroz (mg $\mathrm{dm}^{-3}$ ) nos solos, em função do tempo de incubação (Dourados, MS, 2007/2008).

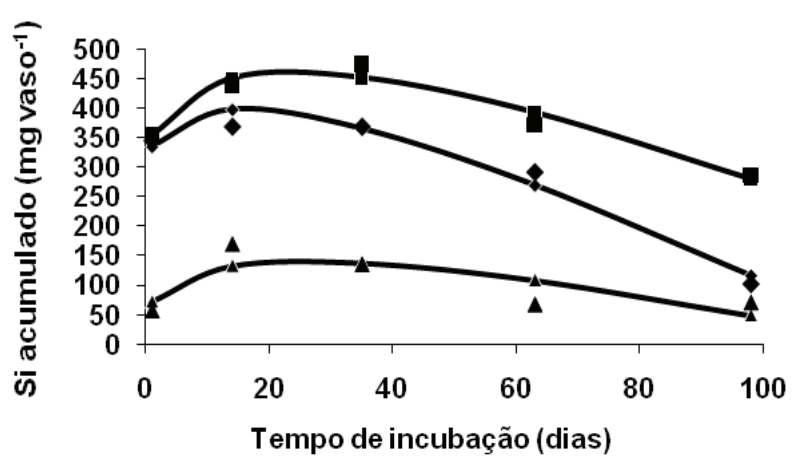

$\begin{array}{lll}\text { 一 } \mathrm{LVd}=283,324+59,4225 * \sqrt{\mathrm{Ti}}-7,70248 * \mathrm{Ti} & \mathrm{R}^{2}=0,97 * * \\ \text { - } \mathrm{LVdf}=290,682+69,1142 * \sqrt{\mathrm{Ti}}-7,09389 * \mathrm{Ti} & \mathrm{R}^{2}=0,95 * * \\ \text { - RQo }=34,6134+41,1993 * \sqrt{\mathrm{Ti}}-4,01976 * \mathrm{Ti} & \mathrm{R}^{2}=0,62 * *\end{array}$

Figura 5. Silício acumulado em plantas de arroz nos três solos, em função do tempo de incubação (Dourados, MS, 2007/2008).
O RQo, o mais arenoso e, portanto, menos tamponado, certamente contribuiu para o menor acúmulo de Si ocorrido aos 28 dias, porque, a partir de uma determinada concentração de cálcio na solução do solo, esta inibe a solubilização dos silicatos, formando complexos silicatados que não são absorvidos pela planta. Ao contrário, no LVdf, por ser mais tamponado (maior resistência do solo em ter seus atributos químicos alterados), o cálcio solubilizado das fontes sendo adsorvido ao sítio de troca favoreceu a solubilização dos silicatos, em menor tempo de incubação, associado à maior acidez potencial do mesmo (Tokura 2004, Martins et al. 2004).

Houve decréscimo no teor e acúmulo de silício, a partir do $25^{\circ}$ e $24^{\circ}$ dias, respectivamente, para o LVdf (Figuras 4 e 5). Isto pode estar, em parte, relacionado com a adubação nitrogenada realizada, pois, segundo Wallace (1989) e Mauad (2001), o incremento da adubação nitrogenada ocasionou redução nos teores de $\mathrm{Si}$, nas plantas de arroz e aveia, sendo o $\mathrm{NH}_{4}^{+}$mais prejudicial que o $\mathrm{NO}_{3}^{-}$, para a absorção de silício.

Quanto maiores as doses de N no solo, maior é a acidificação atribuída à liberação de $\mathrm{H}^{+}$, em função do adubo nitrogenado. Com isto, ocorrerá redução do $\mathrm{pH}$, ocasionando a polimeração do Si (formas de precipitados amorfos) e diminuindo a disponibilidade de Si para o solo e planta (Oliveira et al. 2007).

\section{CONCLUSÕES}

1. Independentemente da fonte de silicato, o maior teor de silício solúvel no solo aumentou na seguinte ordem: RQo $<$ LVd $<$ LVdf.

2. Em todas as classes de solos, a produção de matéria seca de raízes não foi influenciada pela adubação silicatada. Já a matéria seca da parte aérea foi maior, com a aplicação de silicato de cálcio.

3. O maior acúmulo de silício na parte aérea da planta ocorreu entre o segundo e o terceiro tempo de incubação, com concentração mais elevada na classe LVdf.

\section{REFERÊNCIAS}

BARBOSA FILHO, M. P. et al. Resposta do arroz de sequeiro à aplicação de silício. In: FERTBIO, 23., 1998, Caxambu. Anais... Lavras: UFLa/SBCS/SBM, 1998. 
BARBOSA FILHO, M. P. et al. Importância do silício para a cultura do arroz: uma revisão de literatura. Informações Agronômicas, Piracicaba, n. 89, p. 1-8, 2000. Encarte técnico.

BITTENCOURT, M. F. et al. Concentração de silício e $\mathrm{pH}$ do solo afetados pela incubação de diferentes fontes silicatadas no solo. In: SIMPÓSIO SOBRE SILÍCIO NA AGRICULTURA, 3., 2004, Uberlândia. Anais... Uberlândia: GPSI/ICIAG/UFU, 2004. 1 CD-ROM.

BRASIL. Decreto $n^{\circ} 4954$, de 14 de janeiro de 2004, Aprova o regulamento da lei $\mathrm{n}^{\circ} 6894$ de 16 de janeiro de 1980, que dispõe sobre inspeção e fiscalização da produção e do comércio de fertilizantes, corretivos, inoculantes ou biofertilizantes destinados à agricultura, e dá outras providências. Diário Oficial da República Federativa do Brasil, Brasília, DF, 15 jan. 2004. Seção 1, p. 2.

CARVAlHO, J. G. Análise de crescimento e produção de grãos da cultura do arroz irrigado por aspersão em função da aplicação de escória de siderurgia como fonte de silício. 2000. 114 f. Dissertação (Mestrado em Agronomia)-Universidade Estadual Paulista, Botucatu, 2000.

CARVALHO-PUPATTO, J. G.; BÜLL, L. T.; KORNDÖRFER, G. H. Alterações químicas no solo em função da aplicação de silício na cultura do arroz. In: SIMPÓSIO SOBRE SILÍCIO NA AGRICULTURA, 3. 2004, Uberlândia. Anais... Uberlândia: GPSI/ICIAG/UFU, 2004. 1 CD-ROM.

COMPANHIA NACIONAL DE ABASTECIMENTO (Conab). Nota explicativa: estoque de arroz. 2008. Disponível em: <http://www.conab.gov.br/conabweb/ download/safra/ArrozSerieHist.xls>. Acesso em: 08 maio 2008.

COMPANHIA NACIONAL DE ABASTECIMENTO (Conab). Safra 2009/2010: produção de grãos. 2010. Disponível em: <http://www.conab.gov.br/conabweb/ download/safra/3graos_09.12.pdf $>$. Acesso em: 26 jul. 2010 .

EMPRESA BRASILEIRA DE PESQUISA AGROPECUÁRIA (Embrapa). Centro Nacional de Pesquisa de Solos. Sistema brasileiro de classificação de solos. Brasília, DF: Embrapa, 2006.

EMPRESA BRASILEIRA DE PESQUISA AGROPECUÁRIA (Embrapa). Centro Nacional de Pesquisa de Solos. Manual de métodos de análise de solo. 2. ed. Rio de Janeiro: Embrapa-CNPS, 1997. (Documentos, 1).

FARIA JÚNIOR, L. A. de et al. Produção de matéria seca, teor e acúmulo de silício em cultivares de arroz sob doses de silício. Ciência e Agrotecnologia, Lavras, v. 33, n. 4, p. 1034-1040, 2009.
GONG, H. et al. Effects of silicon on growth of wheat under drought. Journal of Plant Nutrition, New York, v. 26, n. 5, p. 1055-1063, 2003.

KORNDÖRFER, G. H.; DATNOFF, L. E. Adubação com silício: uma alternativa no controle de doenças da cana-deaçúcar e do arroz. Informações Agronômicas, Piracicaba, v. 70, n. 1, p. 1-5, 1995.

KORNDÖRFER, G. H. et al. Efeito do silicato de cálcio no teor de silício e na produção de grãos de arroz de sequeiro. Revista Brasileira de Ciência do Solo, Viçosa, v. 23, n. 3, p. 635-641, 1999.

KORNDÖRFER, G. H.; PEREIRA, H. S.; NOLLA, A. Análise de silício: solo, planta e fertilizante. Uberlândia: GPSi/ICIAG/UFU, 2004.

LIMA FILHO, O. F. História do uso do silicato de sódio na agricultura. Dourados: Embrapa Agropecuária Oeste, 2009.

LIMA FILHO, O. F. O silicio na produtividade e sanidade agrícola. Dourados: Embrapa Agropecuária Oeste/MAPA, 2005. Folheto informativo.

LINDSAY, W. L. Chemical equilibria in soil. New York: John Wiley, 1979.

LOPES, M. S. Relações entre o pH e a adsorção de fósforo e silício em solos. 1997. 45 f. Dissertação (Mestrado em Solos e Nutrição de Plantas)-Universidade Federal do Rio Grande do Sul, Porto Alegre, 1997.

MARTINS, M. R.; PEREIRA, H. S.; QUEIROZ, A. A. Comportamento de fontes de silício em quatro solos. Horizonte Científico, Uberlândia, v. 1, n. 1, p. 1-19, 2004.

MAUAD, M. Produção de plantas de arroz sob a ação de silício e nitrogênio. 2001. 79 f. Dissertação (Mestrado em Agricultura)-Faculdade de Ciências Agronômicas, Universidade Estadual Paulista, Botucatu, 2001.

MAUAD, M. et al. Teores de silício no solo e na planta de arroz de terras altas com diferentes doses de adubação silicatada e nitrogenada. Revista Brasileira de Ciência do Solo, Viçosa, v. 27, n. 5, p. 867-873, 2003.

NOVAIS, R. F.; NEVES, J. C. L.; BARROS, N. F. de. Ensaio em ambiente controlado. In: OLIVEIRA, A. J. et al. (Coords.). Métodos de pesquisa em fertilidade do solo. Brasília, DF: Embrapa-SEA, 1991. p. 189-253.

OLIVEIRA, L. A. de; KORNDÖRFER, G. H.; PEREIRA, A. C. Acumulação de silício em arroz em diferentes condições de $\mathrm{pH}$ da rizosfera. Revista Brasileira de Ciência do Solo, Viçosa, v. 31, n. 4, p. 685-690, 2007.

PAIM, L. A. Contaminação do solo por metais pesados: silício e fósforo como agentes amenizadores. 2002. $67 \mathrm{f}$. Dissertação (Mestrado em Ciências)-Universidade Federal de Lavras, 2002. 
PEREIRA, H. S. et al. Extratores de silício disponível em escórias e fertilizantes. Revista Brasileira de Ciência do Solo, Viçosa, v. 27, n. 2, p. 265-274, 2003.

PRADO, R.; FERNANDES, F. M.; NATELE, W. Uso agrícola da escória de siderurgia no Brasil: estudo na cultura da cana-de-açúcar. Jaboticabal: Funep, 2001.

RAMOS, L. A.; KORNDORFER, G. H.; NOLLA, A. Acúmulo de silício em plantas de arroz do ecossistema. Bragantia, Campinas, v. 67, n. 3, p. 751-757, 2008.

RIBEIRO JÚNIOR, J. I. Análises estatísticas no SAEG. Viçosa: UFV, 2001.

SINGER, M. J.; MUNNS, D. N. Soils: introduction. 4. ed. New Jersey: Prentice Hall, 1999.
TOKURA, A. M. Efeito do silício nas frações fosfatadas de solos cultivados com arroz e feijoeiro. 2004. 125 f. Tese (Doutorado em Solos e Nutrição de Plantas)-Universidade Federal de Lavras, Lavras, 2004.

TOKURA, A. M. et al. Silício e fósforo em diferentes solos cultivados com arroz de sequeiro. Acta Scientiarum Agronomy, Maringá, v. 29, n. 1, p. 9-16, 2007.

WALLACE, A. Relationships among nitrogen, silicon, and heavy metal uptake by plants. Soil Science, New Brunswick, v. 147, n. 6, p. 457-460, 1989. 